\title{
AÇÕES EDUCATIVAS COM ENFOQUE POSITIVO EM PROGRAMA DE CONSERVAÇÃO AUDITIVA E SUA AVALIAÇÃO
}

\author{
Positive focus in educational interventions \\ in a hearing conservation program and its evaluation
}

\author{
Luciana Bramatti ${ }^{(1)}$, Thaís Catalani Morata ${ }^{(2)}$, Jair Mendes Marques ${ }^{(3)}$
}

\section{RESUMO}

Objetivo: avaliar o conhecimento adquirido pelos trabalhadores de uma empresa frigorífica após uma ação educativa sobre proteção auditiva. Métodos: foram comparadas as atitudes, intenções e comportamentos de proteção da audição adotados por 61 trabalhadores pré e pós-treinamento, avaliando a efetividade das mensagens através do uso de estímulos positivos. Foram utilizados os questionários "Crenças e Atitudes sobre Proteção Auditiva e Perda Auditiva", os quais foram aplicados antes e após a intervenção na forma de treinamento coletivo. Resultados: os escores dos questionários sobre a percepção de suscetibilidade de adquirir uma perda auditiva e a percepção de obstáculos para uma ação preventiva se mostraram associados às variáveis sexo e tempo de empresa; a percepção de severidade das conseqüências de uma perda auditiva associada ao nível de ruído; normas sociais associada ao tempo de empresa, e a auto-eficácia associada ao resultado da audiometria. Conclusão: o treinamento com enfoque positivo ocasionou mudanças significativas na percepção de benefícios e de obstáculos de uma ação preventiva em comparação ao grupo de trabalhadores que não recebeu treinamento. Esse estudo possibilitará uma intervenção cujo foco será nas áreas consideradas mais deficitárias com a elaboração de propostas e materiais mais específicos e eficazes para os treinamentos que fazem parte do Programa de Conservação Auditiva. O uso de um questionário sobre as crenças e atitudes como o selecionado permite a identificação de temas que necessitam de clarificação em ações educativas.

DESCRITORES: Audição; Dispositivos de Proteção das Orelhas; Saúde do Trabalhador; Ruído

\section{INTRODUÇÃO}

A perda auditiva é uma das doenças ocupacionais mais comuns nos países industrializados. No Brasil, a perda auditiva induzida pelo ruído (PAIR) está entre os principais problemas de saúde dos trabalhadores ${ }^{1}$ e tem sido apontada, como uma

(1) Fonoaudióloga; Universidade de Passo Fundo; Mestre em Distúrbios da Comunicação pela Universidade Tuiuti do Paraná.

(2) Fonoaudióloga; Universidade Tuiuti do Paraná; Doutora em Distúrbios da Comunicação pela University of Cincinnati; Pós-doutorado no National Institute for Occupational Safety and Health, USA.

(3) Engenheiro Químico; Universidade Tuiuti do Paraná; Doutor em Ciências Geodésicas Universidade Federal do Paraná. das patologias de mais elevada ocorrência ${ }^{2}$. Os trabalhadores acometidos com perda auditiva profissional estão sujeitos ao isolamento social, que é o resultado de comunicação prejudicada com a família e amigos; a diminuição na habilidade para monitorar o ambiente de trabalho (sinais de advertência); ao risco mais alto de acidentes no local de trabalho e à qualidade reduzida de vida em função do zumbido inflexível ${ }^{3}$.

Com o objetivo de prevenir perdas auditivas associadas ao trabalho, foram criados os Programas de Conservação Auditiva (PCA), como um conjunto de medidas a serem desenvolvidas com o objetivo de prevenir a instalação ou evolução de perdas da audição ${ }^{4}$. Vários pesquisadores e profissionais que atuam na saúde do trabalhador exposto ao ruído indicam que dentro das atividades propostas 
nos programas de conservação auditiva, devem ser educados e treinados todos os trabalhadores e gerentes sobre este programa, enfatizando o papel a ser desempenhado por cada um deles nos programas preventivos. Eles têm que receber treinamento apropriado para permitir e cumprir os deveres prosperamente ${ }^{5}$. Também devem ser informados os consultores, inclusive médicos ou audiologistas que administram exames de seguimento, sobre os cuidados da empresa em realizar políticas para prevenir as perdas auditivas ${ }^{5,6}$.

Os trabalhadores necessitam ser bem informados das razões e dos requerimentos do programa como um todo, pois o sucesso depende, em grande parte, da educação do trabalhador relativa a todos os aspectos do programa ${ }^{7}$. O treinamento e a motivação dos trabalhadores em relação à conservação auditiva são as ferramentas mais importantes para a utilização adequada e melhor eficácia dos protetores auriculares ${ }^{8}$. As estratégias a serem utilizadas nos treinamentos dependem das características da população-alvo, das condições proporcionadas pela empresa e, principalmente, das metas a serem alcançadas. Como em qualquer área de atuação, os profissionais envolvidos devem buscar o reconhecimento da população-alvo e as características das exposições para definir a política adequada do PCA ${ }^{9}$.

Em estudo realizado em 2001, para a implantação e execução de um PCA, as autoras buscaram uma maior proximidade com os colaboradores da empresa, procurando conhecer as necessidades e prioridades dos mesmos, comprovando assim, a importância da cultura e da história, pois é através da linguagem deste povo que podemos estabelecer relações. E, a partir destas relações, é possível desencadear transformações de uma comunidade, alcançando desta forma o objetivo da educação em saúde ${ }^{10}$. Qualquer informação a respeito de prevenção auditiva deve ser veiculada em uma linguagem adequada e interessante, sempre trabalhando com reforço positivo ${ }^{7}$. As estratégias de treinamento e informações devem ser arrojadas, objetivas, integrativas e convincentes ${ }^{11}$, pois mantém a importância da proteção viva na memória de todos, com o passar do tempo ${ }^{1}$.

Um estudo publicado em 1991 comparou anúncios de saúde de televisão positivos e negativos de contextos de saúde múltiplos, inclusive AIDS, fumo, álcool e hipertensão arterial, entre outros. Foi concluído que os indivíduos se mostraram mais atentos (avaliado pelo tempo de reação secundária) para anúncios positivos, mas sua memória (avaliada por latência de reconhecimento) foi melhor para anúncios negativos ${ }^{12}$. Em outro estudo, realizado com 307 trabalhadores de uma mina de carvão foram utilizados cartões postais com mensagens persuasivas positivas, neutras e negativas relacionadas à proteção auditiva. Como resultado, constatou-se que as mensagens positivas foram mais eficazes do que as mensagens neutras ou negativas para impedir que os mecanismos defensivos de proteção auditiva desaparecessem com o tempo ${ }^{13}$. Em estudo realizado em 2006, cujo objetivo foi avaliar a eficácia da intervenção para promoção do uso de proteção auditiva, a intervenção mostrou-se significativa com efeito de curto prazo, medido imediatamente após a intervenção. Para o efeito a longo prazo, medido um ano após a intervenção, os grupos mostraram aumento significativo ( $7 \%$ vs $6 \%$ ) a partir de pré-intervenção e pós-intervenção ${ }^{14}$. Outro estudo indicou que intervenções realizadas individualmente mostram uma promessa de mudança de comportamento maior nos trabalhadores em relação à proteção auditiva ${ }^{15}$.

O objetivo deste estudo foi avaliar o conhecimento adquirido pelos trabalhadores de uma empresa frigorífica após uma ação educativa na forma de treinamento enfatizando a importância da proteção auditiva, utilizando mensagens com enfoque positivo.

\section{MÉTODOS}

Foram comparadas as atitudes, intenções e comportamentos de proteção da audição adotados pelos trabalhadores antes e depois de intervenção na forma de treinamento com ações educativas, avaliando a efetividade do treinamento com o uso de mensagens e estímulos positivos.

Para alcançar o objetivo proposto, foram utilizados os questionários "Crenças e Atitudes sobre Proteção Auditiva e Perda Auditiva" ${ }^{3}$, os quais foram aplicados antes e após da intervenção na forma de treinamento coletivo (Figuras 1 e 2).

A seleção da amostra foi aleatória e ocorreu durante a realização de exames periódicos de audiometria no período de junho a julho de 2006. Como critério de inclusão no estudo foi considerado o tempo mínimo de seis meses de empresa, exposição a níveis de pressão sonora superior a 85dBA e utilização de protetor auditivo tipo concha. Inicialmente, foram selecionados 93 trabalhadores para participação e destes, três trabalhadores não completaram sua participação devido a demissão, 13 trabalhadores não participaram por estarem em férias, dois por afastamento das atividades e 14 não compareceram para responder ao segundo questionário. Todos os 61 trabalhadores participantes (45 do sexo masculino e 16 do sexo feminino), já possuíam avaliações auditivas realizadas pela autora. A avaliação auditiva respeita todos os 


\section{QUESTIONÁRIO A}

Questionário aprovado em 13/06/2002

OMB № 0920-0552

A carga (média de tempo) desta coleta de informações é 12 minutos por resposta, incluindo o tempo para instruções de revisão, pesquisando fontes de dados existentes, reunindo e mantendo os dados necessários, e completando e revisando a coleta de informações. Um órgão não pode conduzir ou ser responsável, e não é exigido que uma pessoa responda a uma coleta de informações, a menos que apresente um número válido de OMB. Envie comentários a respeito desta avaliação de carga ou qualquer outro aspecto desta coleta de informações, incluindo sugestões para reduzir esta carga para CDC, Project Clearance Officer, 1600 Clifton Rd., M/S D24, Atlanta, GA 30333, ATTN: PRA (0920). Não envie o questionário completo para este endereço.

Nome:

Ocupação:

Data: Data de nascimento:

Por favor leia cada item e circule o número que melhor descreve sua opinião sobre a afirmação. Lembre-se, não há resposta certa ou errada! Estamos interessados em suas opiniões.

1. Penso que posso trabalhar perto de barulho alto sem que isso cause danos a minha audição.

2. Seria mais difícil para as pessoas conversarem comigo se eu perdesse parte da minha audição.

3. Onde eu trabalho há protetores auditivos prontamente disponíveis para eu usar.

4. Nem sempre posso dizer quando preciso usar protetores auditivos.

5. Estou convencido de que posso evitar perda de audição usando protetores auditivos.

6. Protetores externos são muito quentes e pesados para eu usar durante meu trabalho.

7. É difícil para ouvir sinais de advertência como back-up beeps se eu estiver usando protetores auditivos.

8. Não posso usar protetores porque preciso ouvir as pessoas falando comigo enquanto trabalho.

9. Conseguir protetores auditivos para usar no trabalho não é conveniente para mim.

10. Não pretendo usar protetores quando eu estiver próximo a ferramentas ou equipamentos que produzam altos ruídos.

11. Meus colegas geralmente usam protetores quando trabalham em ambiente com barulho arriscado.

12. Acredito que sei como ajustar e usar os protetores auditivos.

13. Acredito que a exposição ao barulho alto pode prejudicar minha audição.

14. Não penso que seria uma grande desvantagem perder parte da minha audição por ter trabalhado em ambiente muito barulhento.

15. Posso dizer quando um protetor interno precisa ser substituído.

16. Não posso proteger minha audição a menos que eu use protetores auditivos em ambientes muito barulhentos.

17. Protetores externos fazem muita pressão em minhas orelhas para serem confortáveis. 18. Usar protetores não me priva de ouvir sons importantes feitos pelas ferramentas ou máquinas.

19. Posso entender as falas suficientemente bem para fazer meu trabalho enquanto estou usando protetores.

20. No trabalho, posso escolher entre vários e diferentes protetores para usar.

21. Geralmente uso protetores sempre que estou trabalhando perto de barulho alto ou equipamento barulhento.

22. Meus colegas geralmente não usam protetores quando precisam trabalhar em áreas barulhentas.

23. Se meus colegas de trabalho perguntassem eu poderia mostrar a eles a maneira correta de ajustar e usar protetores auditivos.

24. Se eu realmente quiser manter minha audição, é importante que eu use protetores auditivos todas as vezes que eu estiver perto de barulho alto.

25. Protetores podem ser confortáveis se ajustados corretamente.

26. Mesmo quando o local não é barulhento algumas vezes é difícil para eu ouvir quando as pessoas estão falando comigo.

27. Protetores auditivos não são muito caros para eu comprar.

28. Se eu tivesse um protetor auditivo comigo eu o usaria todas as vezes que eu estivesse perto

de qualquer barulho que fosse alto o suficiente para prejudicar minha audição. 


\section{QUESTIONÁRIO B}

Questionário aprovado em 13/06/2002 OMB № 0920-0552

A carga (média de tempo) desta coleta de informações é 12 minutos por resposta, incluindo o tempo para instruções de revisão, pesquisando fontes de dados existentes, reunindo e mantendo os dados necessários, e completando e revisando a coleta de informações. Um órgão não pode conduzir ou ser responsável, e não é exigido que uma pessoa responda a uma coleta de informações, a menos que apresente um número válido de OMB. Envie comentários a respeito desta avaliação de carga ou qualquer outro aspecto desta coleta de informações, incluindo sugestões para reduzir esta carga para CDC, Project Clearance Officer, 1600 Clifton Rd., M/S D24, Atlanta, GA 30333, ATTN: PRA(0920). Não envie o questionário completo para este endereço.

Nome:

Ocupação:

Data:

Data de nascimento:

Por favor leia cada item e circule o número que melhor descreve sua opinião sobre a afirmação. Lembre-se, não há resposta certa ou errada! Estamos interessados em suas opiniões.

\begin{tabular}{|c|c|c|c|c|c|}
\hline & 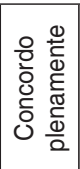 & 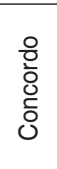 & 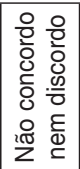 & $\begin{array}{l}\text { 음 } \\
\text { 엄 } \\
\frac{0}{0}\end{array}$ & 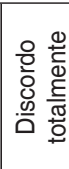 \\
\hline \multicolumn{6}{|l|}{$\begin{array}{l}\text { 1. Não penso que tenho de usar protetores auditivos sempre que estou trabalhando em ambientes } \\
\text { com barulho alto. }\end{array}$} \\
\hline \multicolumn{6}{|l|}{$\begin{array}{l}\text { 2. Não seria mais difícil para as pessoas conversarem comigo se eu perdesse parte da minha } \\
\text { audição. }\end{array}$} \\
\hline \multicolumn{6}{|l|}{$\begin{array}{l}\text { 3. Protetores auditivos não estão prontamente disponíveis para que eu possa usá-los onde } \\
\text { trabalho. }\end{array}$} \\
\hline \multicolumn{6}{|l|}{ 4. Sei quando eu deveria usar protetores auditivos. } \\
\hline \multicolumn{6}{|l|}{ 5. Se eu usar protetores auditivos posso proteger minha audição de barulho alto. } \\
\hline \multicolumn{6}{|l|}{ 6. Protetores internos são desconfortáveis para usar mesmo quando bem ajustados. } \\
\hline \multicolumn{6}{|l|}{$\begin{array}{l}\text { 7. Mesmo quando estou usando protetores auditivos, ainda posso ouvir os "back-up beeps" ou } \\
\text { outros sinais de advertência. }\end{array}$} \\
\hline \multicolumn{6}{|l|}{$\begin{array}{l}\text { 8. Ainda posso ouvir as pessoas falando comigo enquanto faço meu trabalho, mesmo quando } \\
\text { estou usado meus protetores auditivos. }\end{array}$} \\
\hline \multicolumn{6}{|l|}{ 9. É conveniente eu conseguir protetores auditivos para usar no trabalho. } \\
\hline \multicolumn{6}{|l|}{$\begin{array}{l}\text { 10. Pretendo usar protetores auditivos quando estou perto de ferramentas ou equipamentos } \\
\text { ruidosos. }\end{array}$} \\
\hline \multicolumn{6}{|l|}{$\begin{array}{l}\text { 11. Meus colegas de trabalho geralmente não usam protetores auditivos quando trabalham em } \\
\text { ambiente com barulho arriscado. }\end{array}$} \\
\hline \multicolumn{6}{|l|}{ 12. Não tenho certeza que sei como ajustar e usar protetores auditivos. } \\
\hline \multicolumn{6}{|l|}{ 13. Se eu não proteger meus ouvidos, o barulho alto pode prejudicar minha audição. } \\
\hline \multicolumn{6}{|l|}{$\begin{array}{l}\text { 14. Não me aborreceria se eu perdesse parte da minha audição por trabalhar em ambiente } \\
\text { barulhento. }\end{array}$} \\
\hline \multicolumn{6}{|l|}{ 15. Não posso dizer quando um protetor interno ou externo precisa ser substituído. } \\
\hline \multicolumn{6}{|l|}{ 16. Não perderei minha audição se eu usar protetores auditivos em ambientes barulhentos. } \\
\hline \multicolumn{6}{|l|}{ 17. Posso encontrar um protetor externo que não seja muito quente ou pesado para eu usar. } \\
\hline \multicolumn{6}{|l|}{$\begin{array}{l}\text { 18. Não posso ouvir barulhos que acusem problemas nas minhas máquinas ou ferramentas se eu } \\
\text { usar protetores auditivos. }\end{array}$} \\
\hline \multicolumn{6}{|l|}{$\begin{array}{l}\text { 19. Não posso ouvir as falas suficientemente bem para fazer meu trabalho se estou usando } \\
\text { protetores auditivos. }\end{array}$} \\
\hline \multicolumn{6}{|l|}{$\begin{array}{l}\text { 20. Não consigo encontrar um protetor auditivo que eu goste de usar, porque não há uma } \\
\text { variedade grande o suficiente para eu escolher em meu local de trabalho. }\end{array}$} \\
\hline \multicolumn{6}{|l|}{ 21. Geralmente não uso protetores auditivos quando trabalho em ambiente barulhento. } \\
\hline \multicolumn{6}{|l|}{$\begin{array}{l}\text { 22. Meus colegas de trabalho geralmente usam protetores auditivos quando precisam trabalhar } \\
\text { em áreas barulhentas. }\end{array}$} \\
\hline \multicolumn{6}{|l|}{$\begin{array}{l}\text { 23. Não acho que eu poderia mostrar a um colega a maneira correta de ajustar e usar protetores } \\
\text { auditivos. }\end{array}$} \\
\hline \multicolumn{6}{|l|}{$\begin{array}{l}\text { 24. Preciso usar protetores auditivos todas as vezes que estiver em ambiente barulhento se eu } \\
\text { realmente quiser manter minha audição. }\end{array}$} \\
\hline \multicolumn{6}{|l|}{$\begin{array}{l}\text { 25. Se preciso usar um protetor externo posso conseguir um que possa ser ajustado para que não } \\
\text { haja muita pressão em meus ouvidos. }\end{array}$} \\
\hline \multicolumn{6}{|l|}{$\begin{array}{l}\text { 26. Mesmo em ambiente quieto, às vezes tenho dificuldades em ouvir o que as pessoas estão } \\
\text { dizendo. }\end{array}$} \\
\hline \multicolumn{6}{|l|}{ 27. Protetores auditivos são muito caros para eu comprar. } \\
\hline $\begin{array}{l}\text { 28. Mesmo se eu tivesse um comigo, eu provavelmente não usaria um protetor auditivo todas as } \\
\text { vezes que eu estivesse perto de qualquer barulho que fosse alto o suficiente para prejudicar } \\
\text { minha audição. }\end{array}$ & & & & & \\
\hline
\end{tabular}


critérios sugeridos pela Portaria $\mathrm{n}^{\circ} 19$ do Ministério do Trabalho e pelo Comitê Nacional de Ruído e Conservação Auditiva ${ }^{16}$.

Todos os trabalhadores expostos a ruído igual ou superior a $80 \mathrm{dBA}$ utilizam protetor auricular tipo concha, modelo 3M 1435 ou modelo M.S.A. O nível de ruído foi avaliado pelo Setor de Engenharia de Segurança da empresa, utilizando-se Audiodosímetro 897 Simpson com áudio calibrador operando em circuito de compensação "A" e circuito de resposta lenta (slow). Todas as medições foram realizadas próximas ao ouvido do trabalhador, conforme Portaria $n^{\circ} 3 \cdot 214 / 78$ do Ministério do Trabalho ${ }^{16,17}$.

A pesquisa foi dividida em três partes. Primeiramente foi aplicado um questionário individual aos 61 trabalhadores no momento em que realizaram o exame periódico de audiometria. Após um período de 15 dias, foram sorteados aleatoriamente 50\% da amostra (sem distinção de sexo), para receber o treinamento sobre proteção auditiva. Esse treinamento foi realizado com dois grupos de 12 trabaIhadores e um grupo de 10 trabalhadores. $O$ treinamento foi realizado durante a jornada de trabalho. Após o treinamento, os trabalhadores responderam o segundo questionário. Os demais trabalhadores que não foram sorteados para o treinamento foram chamados para responder ao segundo questionário também durante sua jornada de trabalho.

A avaliação auditiva teve como objetivo descrever o estado da audição dos participantes e verificar se este exerce influência sobre as crenças e atitudes quanto aos temas de conservação auditiva. Foram utilizados os seguintes procedimentos: 1) inspeção do meato acústico: com otoscópio da marca Welch Allyn, que teve a finalidade de investigar a presença de cerume no meato acústico, o que poderia alterar o resultado da audiometria; 2) audiometria realizada em cabina acústica Vibrasom com repouso acústico de 14 horas. O audiômetro utilizado foi da marca Interacoustics, modelo AD 226, com fone TDH-39, calibrado de acordo com as normas internacionais. As freqüências avaliadas na via aérea foram de $250 \mathrm{~Hz}$ a $8 \mathrm{kHz}$ e quando o limiar encontrado fosse maior que $25 \mathrm{~dB}$, também foi realizada a via óssea de $0,5 \mathrm{a} 4 \mathrm{kHz}$.

A classificação utilizada para a interpretação das audiometrias foi a recomendada pela legislação ${ }^{16,17}$. Após a realização dos exames de audiometria e da aplicação do primeiro questionário (versão $A$ ), sorteou-se $50 \%$ da amostra para participar de treinamento coletivo.

O treinamento foi elaborado pela autora, em que foram abordados aspectos referentes ao funcionamento do sistema auditivo, importância da audição, qualidade de vida e os reflexos das alterações auditivas no âmbito social e profissional, utilizando-se mensagens com enfoque nos aspectos positivos referentes à audição. A duração do treinamento foi de 30 minutos, com exposição das informações através de data-show. Foram utilizados slides com imagens, conteúdo escrito e músicas. Durante o treinamento, os trabalhadores receberam orientação e poderiam participar fazendo perguntas para esclarecimentos. No decorrer dos trabalhos, foram utilizadas situações diárias vivenciadas pelos próprios trabalhadores.

Os questionários intitulados "Crenças e atitudes sobre proteção auditiva e perda auditiva" são divididos em duas versões (A e B), com questões sobre o mesmo conteúdo, apresentadas de forma distinta, para uma aplicação em dois momentos. Os originais em inglês foram desenvolvidos e validados por pesquisadores do $\mathrm{NIOSH}^{3}$, dos Estados Unidos, contrato $n^{\circ}$. 211-93-006 e versões em sueco e português foram usadas anteriormente $13,18,19,20$. No Brasil, estão em processo de validação pela presente autora. Estes questionários avaliam as crenças e atitudes dos trabalhadores sobre a prevenção da perda auditiva e como utilizam o protetor auditivo. Cada versão dos questionários ( $A$ e $B$ ) consiste de vinte e oito questões, as quais são subdivididas em dez áreas temáticas, sendo elas: (1) percepção de suscetibilidade de adquirir uma perda auditiva, (2) percepção da severidade das conseqüências de perda auditiva, (3) percepção de benefícios de uma ação preventiva, (4) percepção de obstáculos para ação preventiva / conforto, (5) percepção de obstáculos para ação preventiva / atenuação de sons importantes, (6) percepção de obstáculos para ação preventiva / comunicação, (7) percepção de obstáculos para ação preventiva / conveniência e disponibilidade de proteção auditiva, (8) intenções de comportamento, (9) normas Sociais e (10) auto-eficácia.

As respostas são dadas em uma escala Likert de 1 a 5 , com as respostas variando de "Concordo plenamente", resposta número 1, a "Discordo totalmente", resposta número 5 .

As instruções dadas para o preenchimento orientam o trabalhador a marcar a alternativa que melhor descreve sua opinião sobre a frase. Eles foram informados de que não existem respostas certas ou erradas e o interesse da pesquisa era sua opinião.

As versões $\mathrm{A}$ e $\mathrm{B}$ foram traduzidas por dois profissionais qualificados em língua estrangeira. As duas traduções independentes foram comparadas. Depois de feita a tradução da língua inglesa para a língua portuguesa foi feita a tradução reversa para a língua inglesa para avaliação da adequação da tradução. Após a avaliação da tradução, os questionários (Figuras 1 e 2) foram aplicados 
a um grupo de 10 trabalhadores de outra empresa para avaliar se os mesmos estavam com uma linguagem compreensível para serem utilizados na pesquisa. Após a aplicação os trabalhadores foram questionados sob a compreensão das perguntas e a necessidade de se realizar modificações nas questões. Estes relataram que o questionário era de fácil compreensão.

Após constatação de que os questionários estavam adequados, iniciou-se a aplicação. O questionário (Versão A) foi aplicado individualmente aos trabalhadores com prévia orientação sobre o preenchimento do mesmo, na ocasião da realização do exame de audiometria periódico. O questionário (Versão B) foi aplicado após treinamento coletivo.

A análise dos questionários "Crenças e atitudes sobre proteção auditiva e perda auditiva" foi realizada por área temática e foram utilizados o Teste $\mathrm{t}-$ de Student e o Teste Exato de Fisher na análise estatística dos resultados. O Teste de Mann-Whitney foi usado na comparação dos limiares dos grupos com e sem treinamento. $O$ presente trabalho foi aprovado pelo Comitê de Ética da Universidade Tuiuti do Paraná (UTP) em 08 de novembro de 2006, sob o n 072/2006.

\section{RESULTADOS}

Para a análise dos resultados foram calculados os escores das respostas das versões $A$ e $B$ dos questionários dos dois subgrupos do estudo, aqueles que receberam treinamento e aqueles que não receberam, sendo que quanto maior o escore, menor o nível de informação que a pessoa tem sobre o assunto. Foram também avaliadas as seguintes variáveis em relação ao escore do questionário: sexo, idade, tempo de empresa, nível de ruído e resultados da audiometria.

\section{Perfil Audiométrico}

Foram calculados os limiares médios dos dois grupos (grupo que recebeu o treinamento e o que não recebeu o treinamento). O Teste de MannWhitney demonstrou que não foram encontradas diferenças significativas entre os grupos (Tabela 1, Figura 3)

Os escores dos trabalhadores que receberam treinamento coletivo sobre proteção auditiva foram comparados com os escores dos trabalhadores que não receberam treinamento.

Tabela 1 - Teste de Mann-Whitney para comparação dos limiares dos grupos com e sem treinamento, por orelha (direita, OD e esquerda, OE)

\begin{tabular}{ccccc}
\hline $\begin{array}{c}\text { FREQÜÊNCIAS }(\mathrm{kHz}) \\
\text { OD }\end{array}$ & $\mathrm{n}_{1}$ & $\mathrm{~N}_{2}$ & $\mathrm{Z}$ & $\mathrm{p}$ \\
\hline 0.25 & 34 & 27 & $-0,049822$ & 0,960264 \\
0.5 & 34 & 27 & 0,445548 & 0,655924 \\
1 & 34 & 27 & 0,527582 & 0,597790 \\
2 & 34 & 27 & 0,299935 & 0,764227 \\
3 & 34 & 27 & 0,627253 & 0,530494 \\
4 & 34 & 27 & 0,849356 & 0,395684 \\
6 & 34 & 27 & $-0,353534$ & 0,723688 \\
8 & 34 & 27 & $-0,390344$ & 0,696283 \\
\hline FREQÜÊNCIAS $(\mathrm{kHz})$ & & & & \\
OE & $\mathrm{n}_{1}$ & $\mathrm{~N}_{2}$ & & $\mathrm{z}$ \\
\hline 0.25 & 34 & 27 & $-0,151662$ & 0,879453 \\
0.5 & 34 & 27 & 0,444231 & 0,656876 \\
1 & 34 & 27 & 0,937134 & 0,348690 \\
2 & 34 & 27 & 0,594217 & 0,552368 \\
3 & 34 & 27 & 1,720388 & 0,085363 \\
4 & 34 & 27 & 1,278906 & 0,200931 \\
6 & 34 & 27 & $-0,263028$ & 0,792529 \\
8 & 34 & 27 & $-0,541995$ & 0,587823 \\
\hline
\end{tabular}

$\mathrm{n}_{1}=$ número de sujeitos que receberam treinamento

$\mathrm{n}_{2}=$ número de sujeitos que não receberam treinamento 


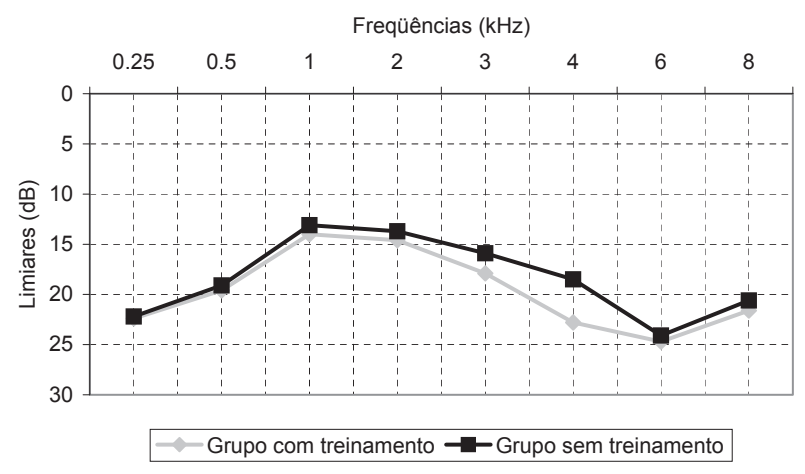

(a)

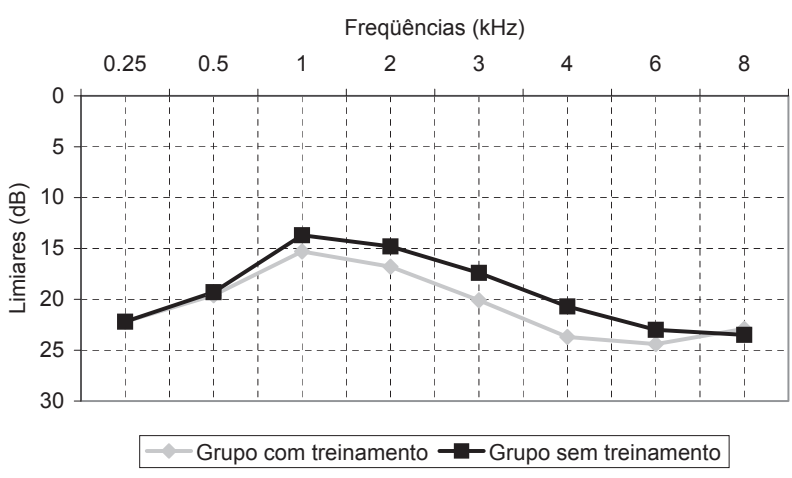

(b)

Figura 3 - Limiares médios para os 2 grupos do estudo na orelha direita (a) e esquerda (b)

Na Tabela 2, Figuras 4 e 5 estão apresentados os resultados no teste t de Student, da comparação dos escores médios dos dois questionários para o grupo que recebeu o treinamento e do que não recebeu o treinamento. Por meio do teste t de Student, nota-se que ao nível de significância de 5\% ocorreu uma diferença significativa entre as respostas dos dois questionários no grupo que recebeu o treinamento com a área temática 4 - percepção de obstáculos para uma ação preventiva $(p<0,05)$, ou seja, os indivíduos treinados aumentaram sua percepção em relação aos indivíduos que não receberam treinamento. Outras associações que se aproximaram do nível de significância selecionado para este estudo foram da área temática 3 - percepção de benefícios de uma ação preventiva e, no grupo que não recebeu treinamento, da área temática 2 percepção da severidade das conseqüências de uma perda auditiva $(p<0,05)$.
$\mathrm{Na}$ Tabela 3 estão os resultados dos testes que avaliaram a significância das associações entre as características dos participantes do estudo e os escores do questionário $\mathrm{B}$, por área temática. Nesta análise, o caso da variável área temática considerou-se as categorias: escores menores que $3 \mathrm{e}$ escores iguais ou maiores que 3; para a variável sexo as categorias foram masculino ou feminino, para a variável idade as categorias consideradas foram 18 a 28 anos e 29 anos ou mais; para a variável tempo de empresa as categorias foram menos de 5 anos e 5 anos ou mais; para a variável nível de ruído as categorias foram até $85 \mathrm{~dB}$ e mais de $85 \mathrm{~dB}$ e para a variável audiometria as categorias foram normal ou alterada.

Ao nível de significância de 5\%, a dependência entre área temática e sexo foi significativa somente com a área temática 1 - percepção de suscetibilidade de adquirir uma perda auditiva, sendo que

Tabela 2 - Resultados do teste t de Student para comparação dos escores médios, por área temática, dos questionários $A$ e $B$, para o grupo que recebeu o treinamento e para o grupo que não recebeu 0 treinamento

\begin{tabular}{ccccc}
\hline \multirow{2}{*}{ ÁREA TEMÁTICA } & \multicolumn{2}{c}{ GRUPO COM TREINAMENTO } & \multicolumn{2}{c}{ GRUPO SEM TREINAMENTO } \\
\cline { 2 - 5 } & Estatística $\mathrm{t}$ & $\mathrm{P}$ & Estatística $\mathrm{P}$ & $\mathrm{P}$ \\
\hline 1 & 0,09022 & 0,928387 & $-0,69825$ & 0,488134 \\
2 & 0,94530 & 0,348175 & $-1,94660$ & $\mathbf{0 , 0 5 7 1 0 2}$ \\
3 & 1,92332 & $\mathbf{0 , 0 5 7 3 7 3}$ & 1,09685 & 0,276081 \\
4 & 2,36951 & $\mathbf{0 , 0 1 9 8 7 8 ^ { * }}$ & 1,12067 & 0,265866 \\
5 & 1,25566 & 0,214026 & 1,57917 & 0,120603 \\
6 & 0,83204 & 0,407411 & 1,38066 & 0,171326 \\
7 & 0,74197 & 0,459506 & $-0,70190$ & 0,484312 \\
8 & $-1,58322$ & 0,116560 & $-0,97995$ & 0,330101 \\
9 & $-1,08530$ & 0,281737 & $-1,34122$ & 0,185792 \\
10 & $-0,24910$ & 0,803682 & $-0,37350$ & 0,709513 \\
\hline
\end{tabular}

Nota: As correlações significativas estão em negrito, seguidas por um asterisco, enquanto que as que se aproximaram do nível de significância selecionado estão em negrito, sem asterisco. 


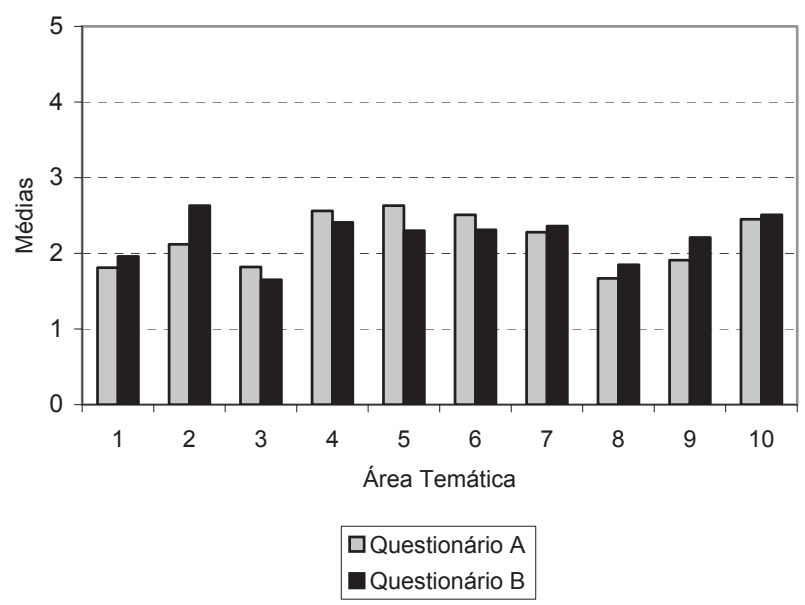

Figura 4 - Comparação dos escores médios das respostas dos questionários $\mathrm{A}$ e $\mathrm{B}$, por área temática, para 0 grupo que não recebeu treinamento

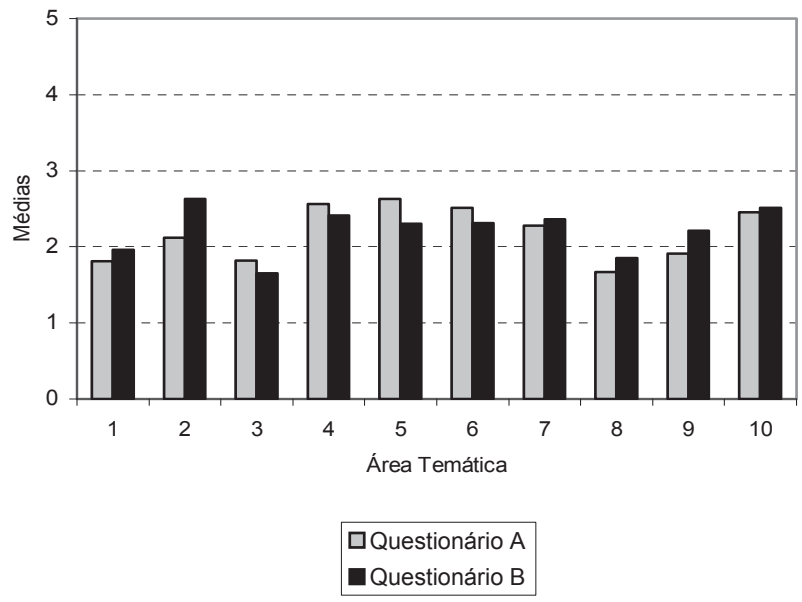

Figura 5 - Comparação dos escores médios das respostas dos questionários $\mathrm{A}$ e $\mathrm{B}$, por área temática, para 0 grupo que recebeu treinamento

Tabela 3 - Resultados do teste exato de Fisher testando a dependência entre a área temática e cada uma das variáveis: treinamento, sexo, idade, tempo de empresa, nível de ruído e audiometria - questionário $B$

\begin{tabular}{ccccccc}
\hline $\begin{array}{c}\text { ÁREA } \\
\text { TEMÁTICA }\end{array}$ & $\begin{array}{c}\text { TREINA- } \\
\text { MENTO }\end{array}$ & SEXO & IDADE & $\begin{array}{c}\text { TEMPO DE } \\
\text { EMPRESA }\end{array}$ & $\begin{array}{c}\text { NÍVEL DE } \\
\text { RUÍDO }\end{array}$ & $\begin{array}{c}\text { AUDIO- } \\
\text { METRIA }\end{array}$ \\
\hline 1 & 0,2122 & $\mathbf{0 , 0 2 7 8 ^ { * }}$ & 0,3474 & $\mathbf{0 , 0 0 1 3 ^ { * }}$ & 0,7501 & 0,7279 \\
2 & 0,5203 & 0,7075 & 0,5187 & 0,3471 & $\mathbf{0 , 0 9 7 0}$ & 1,0000 \\
3 & 0,3666 & 0,3288 & 0,6494 & 0,3533 & 1,0000 & 0,5965 \\
4 & 0,3146 & 0,2370 & 1,0000 & 0,7414 & 0,1022 & 1,0000 \\
5 & 0,5801 & 0,5163 & 1,0000 & 0,2628 & 0,7770 & 0,2122 \\
6 & 0,2600 & 1,0000 & 1,0000 & $\mathbf{0 , 0 4 1 5 ^ { * }}$ & 0,7703 & 0,7473 \\
7 & 0,3185 & $\mathbf{0 , 0 9 9 7}$ & 0,7412 & 0,7297 & 1,0000 & 0,2400 \\
8 & 0,7172 & 0,6669 & 1,0000 & 0,2566 & 1,0000 & 1,0000 \\
9 & 1,0000 & 0,4186 & 1,0000 & $\mathbf{0 , 0 8 4 0}$ & 0,5640 & 0,1932 \\
10 & 0,3988 & 0,7388 & 0,4122 & 1,0000 & $\mathbf{0 , 0 4 6 2}$ & $\mathbf{0 , 0 1 2 9 ^ { * }}$ \\
\hline
\end{tabular}

Nota: As correlações significativas estão em negrito, seguidas por um asterisco, enquanto que as que se aproximaram do nível de significância selecionado estão em negrito, sem asterisco.

o sexo masculino apresentou escores maiores em relação ao sexo feminino (escores maiores representam um menor nível de informação), o que pode demonstrar que o sexo masculino apresenta menor percepção de suscetibilidade de adquirir uma perda auditiva do que o sexo feminino. Outro resultado significativo foi entre as áreas temáticas 1 - percepção de suscetibilidade de adquirir uma perda auditiva e 6 - percepção de obstáculos para uma ação preventiva (comunicação) e tempo de empresa, sendo que os trabalhadores com maior tempo de empresa apresentaram escores maiores, ou seja, apresentam uma percepção dos riscos de adquirir uma perda auditiva menor. Também foi significativa a correlação entre a área temática 10 - auto-eficácia e o nível de ruído, sendo que os trabalhadores expostos a um nível de ruído inferior a $85 \mathrm{~dB}$ apresentaram escores maiores. O conceito de auto-eficácia reflete o grau em que o indivíduo acredita na sua própria capacidade de atingir determinado objetivo e, no contexto do presente estudo, a auto-eficácia traduz a crença do trabalhador na sua própria capacidade de prevenir a ocorrência de uma perda auditiva. Essas correlações se mostram pertinentes, pois o indivíduo pode se perceber mais vulnerável se o nível de ruído for muito elevado. Finalmente, outro resultado significativo foi entre a área temática 10 - auto-eficácia e a audiometria, ocorrendo esco- 
res maiores para aqueles com audiometria normal, pois o resultado audiométrico fornece bases para o estabelecimento da auto-eficácia.

Observou-se também neste estudo, correlações muito próximas ao nível de significância selecionado, sendo estas correlações entre a área temática 2 - percepção severidade das conseqüências de uma perda auditiva e nível de ruído (inferior a 85dBA); entre a área temática 7 - percepção obstáculos de uma ação preventiva - comunicação/disponibilidade e sexo (sexo masculino e o sexo feminino com escores iguais) e entre a área temática 9 normas sociais e tempo de empresa sendo que, trabalhadores com maior tempo de empresa apresentaram escores maiores.

\section{DISCUSSÃO}

Esta proposta de trabalho, além de mostrar o comportamento e atitudes dos trabalhadores com relação à proteção auditiva, serviu para conhecer qual a interferência que um treinamento com enfoque positivo poderia ocasionar nos trabalhadores, avaliando com isso a efetividade deste treinamento. Esse estudo possibilitará, posteriormente, uma intervenção cujo foco será nas áreas consideradas mais deficitárias.

Nas análises realizadas por área temática observou-se correlação estatisticamente significativa entre a variável sexo e a percepção da suscetibilidade de adquirir perda auditiva, sendo que neste caso, o sexo masculino obteve escores maiores em relação ao sexo feminino (escores mais altos representam um menor nível de informação), o que pode demonstrar que o sexo masculino apresenta menor percepção de suscetibilidade de adquirir uma perda auditiva do que o sexo feminino.

Houve correlação significativa entre o tempo de empresa e as áreas temáticas, suscetibilidade de adquirir uma perda auditiva e percepção de obstáculos para uma ação preventiva - comunicação. Este resultado aponta para o fato de que os trabaIhadores com maior tempo de empresa apresentam uma menor percepção dos riscos de adquirir uma perda auditiva. Estes trabalhadores, talvez por terem tomado as precauções recomendadas, ou talvez por seus audiogramas terem se mantido inalterados, não acreditam que podem adquirir uma perda auditiva. Em relação à percepção de dificuldades na comunicação com o uso de proteção auditiva e o tempo de empresa, pode ser explicado pelo fato de que a empresa adota somente um modelo de protetor auditivo (tipo concha), devido às características de seu trabalho, sendo obrigatório o seu uso durante toda a jornada de trabalho, o que nem sempre agrada aos trabalhadores, e não vai ao encontro das recomendações sugeridas ${ }^{3,5,8}$, o qual sugere que o próprio trabalhador faça a opção do modelo de protetor que julga mais confortável para o uso.

Também foi significativa a correlação entre o nível de ruído (inferior a $85 \mathrm{dBA}$ ) e a área temática 10 - auto-eficácia, e, finalmente, outro resultado significativo foi entre a auto-eficácia, e a audiometria, ocorrendo escores maiores para aqueles com audiometria normal. O conceito de auto-eficácia reflete o grau em que o indivíduo acredita na sua própria capacidade de atingir determinado objetivo. No contexto do presente estudo, a auto-eficácia traduz a crença do trabalhador na sua própria capacidade de prevenir a ocorrência de uma perda auditiva. Neste grupo de trabalhadores, esta crença se mostrou ser influenciada pelo nível de ruído do setor de trabalho e pelo resultado audiométrico. Essas correlações se mostram pertinentes, pois o indivíduo pode se perceber mais vulnerável se o nível de ruído for muito elevado. O resultado audiométrico lhe dá bases para o estabelecimento desta auto-eficácia. A relação entre nível de ruído e autoeficácia já havia sido descrita num estudo anterior com trabalhadores suecos, o qual utilizou o mesmo questionário, porém o estudo anterior não observou a correlação entre auto-eficácia e resultado audiométrico, mas neste mesmo estudo, foram identificadas diferenças significativas referentes ao mau uso do protetor auditivo relacionado à idade, tempo de empresa e grupos de diferentes empresas ${ }^{18}$.

Como recomendado ${ }^{13}$, pesquisas poderiam ser utilizadas em trabalhadores antes e depois de um treinamento para avaliar se o treinamento influenciou ou não a atitude e comportamento dos trabaIhadores, considerando a questão da prevenção da perda auditiva e também para avaliar a efetividade real de um programa de conservação auditiva.

Instrumentos como os questionários utilizados nesta pesquisa servem de parâmetro para avaliar o nível de conhecimento apresentado pelos trabalhadores antes e após uma intervenção, no caso desta pesquisa, na forma de treinamento coletivo. Podese considerar um instrumento valioso, pois por meio dos dados coletados, consegue-se estimar o alcance e a efetividade do treinamento realizado.

A escolha de estratégias educacionais e de motivação é essencial ao sucesso do treinamento do PCA. As técnicas usadas e o conteúdo selecionado para apresentação devem ser adaptados às necessidades particulares dos participantes ${ }^{4}$. Cartazes, quadros de anúncios, folhetos informativos, etc. podem ser usados como uma lembrança constante da importância que a empresa coloca na conservação da audição. 
Sessões de treinamento especiais ou reuniões de segurança regularmente planejadas devem endereçar políticas da empresa, resultado da exposição ao ruído, monitoramento ambiental deste e as avaliações de seu efeito na audição. Estas sessões de treinamento não devem ser limitadas a mostrar unicamente um filme, mas devem ser apresentadas de forma interessante e atrativa por um profissional competente e com conhecimentos sobre conservação da audição. O conteúdo dos treinamentos deve ser variado e continuamente atualizado ${ }^{3,5}$. Além desse episódio de treinamento, deve ser oferecido um processo educacional contínuo.

As estratégias a serem utilizadas nos treinamentos dependem das características da populaçãoalvo, das condições proporcionadas pela empresa e, principalmente, das metas a serem alcançadas ${ }^{9}$. Como em qualquer área de atuação, os profissionais envolvidos devem buscar o reconhecimento da população-alvo e as características das exposições para definir a política adequada do PCA.

Um bom treinamento deve ser elaborado baseando-se em Campanhas de Conservação Auditiva que contenham uma idéia central a ser veiculada ${ }^{8}$. A partir daí todos os recursos didáticos de apoio devem ser utilizados como: faixas, cartazes, cartilhas, palestras, brindes, stands, etc. Qualquer informação a respeito de prevenção auditiva deve ser veiculada em uma linguagem adequada e interessante para o trabalhador. Mensagens positivas demonstraram-se eficientes em ações preventivas em saúde auditiva dirigidas aos trabalhadores ${ }^{13-19,20 .}$

\section{CONCLUSÃO}

Os resultados desta pesquisa mostraram que o treinamento com enfoque positivo ocasionou mudanças significativas no comportamento e conhecimento dos trabalhadores em relação à proteção auditiva, o que pôde ser comprovado através das análises realizadas, principalmente nas áreas temáticas percepção de benefícios para uma ação preventiva - auto-eficácia, comunicação, e normas sociais.

Observou-se que, apesar de ter ocorrido mudanças significativas em determinadas áreas temáticas, justifica-se a necessidade de um enfoque maior sobre os protetores auditivos no treinamento, reforçando questões como uso, manuseio, limpeza e conservação e a relação destes cuidados com a efetividade da proteção do protetor auditivo e o que isto reflete na proteção auditiva e na redução dos riscos do ruído ao organismo.

Sabe-se que, o reflexo da implantação de Programas de Conservação Auditiva vai muito além do cumprimento da legislação. Desenvolver programas educativos é um ato de inteligência, pois desenvolve a conscientização, resultando em benefícios diretos tanto para a empresa, quanto para o trabalhador. Todos saem ganhando. Ganha o trabalhador na sua qualidade de vida, ganha a empresa por cumprir a legislação e melhorar a questão da higiene industrial e ganha a sociedade, pela empresa cumprir seu papel social na visão e concepção de saúde para todos.

\section{ABSTRACT}

Purpose: to evaluate the efficacy of an educational intervention on hearing protection in a group of 61 workers at a meat packing company. Methods: one group of workers participated in a training session that used positive messages; the other group of workers received no intervention. The two versions of the NIOSH "Beliefs and Attitudes on Hearing Loss Prevention" questionnaire were used to assess changes before and after the intervention. Workers who received the training using positive messages showed significant changes in their perception of the benefits and obstacles to preventive action in comparison with the group that did not receive any intervention. Results: the post-test scores for perception of susceptibility to developing a hearing loss and obstacles to preventive actions were significantly associated with gender and tenure; perception of severity of the consequences of a hearing loss was associated with noise level; social norms were associated with tenure; and self-efficacy was associated with audiometric thresholds. Conclusion: this study will make easier the development of interventions focused on the areas where workers lack information, and allow for educational materials for hearing loss prevention programs to be appropriately addressed to relevant obstacles. The use of a questionnaire on beliefs and attitudes such as the one selected for this study allows the identification of issues that require clarification in educational interventions.

KEYWORDS: Hearing; Ear Protection Devices; Occupational Health; Noise 


\section{REFERÊNCIAS}

1. Gabas G. Escute bem e proteja-se. Rev Proteção. 2007; 181:54-61.

2. Costa EA, Morata TC, Kitamura S. Patologia do ouvido relacionada com o trabalho. In: Mendes $R$. Patologia do trabalho. 2. ed. São Paulo: Atheneu; 2003. p.1253-82.

3. National Institute for Occupational Safety and Health. (NIOSH). Preventing occupational hearing loss: a practical guide. DHHS Pub. n. 96-110, p.1, Cincinnati: DHHS, CDC, NIOSH: 1996.

4. Morata TC, Santos UP. Anatomia e fisiologia da audição. In: Santos UP, organizador. Ruído: riscos e prevenção. São Paulo: Hucitec; 1994. p.7-23.

5. Royster JD, Royster LH. Hearing conservation programs: practical guidelines for success. Chelsea: Lewis Publishers; 1990. p.15-22.

6. Ferreira D. A fonoaudiologia, o direito previdenciario e a perda auditiva induzida pelo ruido. In: Morata TC, Zucki F, organizador. Caminhos para a saúde auditiva ambiental-ocupacional. São Paulo: Plexus; 2005. p.202-14.

7. Berger MS. The ardent hearing conservationist. Spectrum Suppl. 2001; 18(1):17-8.

8. Bernardi APA. Audiologia ocupacional. São José dos Campos: Pulso; 2003. p.49-65

9. Nudelmann AA, Costa EA, Seligman J, Ibañez RN. PAIR: perda auditiva induzida pelo ruído. vol 2. Rio de Janeiro: Revinter; 2001. p.51-61

10. Azevedo AN, Athayde DSM de, Reis ML dos, Giovanella N. Trabalho de educação e saúde fonoaudiológica em olarias. Fono Atual. 2002; 5(21):36-9.

11. Rios A.L. Implantação de um programa de conservação auditiva: enfoque fonoaudiológico. [tese] Ribeirão preto (SP): Universidade de São Paulo; 2007.

12. Reeves BR, Newhage J, Maibac E, Basil M, Kuz K. Negative and positive television messages: effects of message type and context on attention and memory. Am Behav Sci. 1991; 34(6):679-94.
13. Stephenson MT, Witte K, Vaught C, Quick BL, Booth-Butterfield S, Patel D, Zuckerman C. Using persuasive messages to encourage voluntary hearing protection among coal miners. J Safety Res. 2005; 36(1):9-17.

14. Hong O, Ronis DL, Lusk SL, Kee GS. Efficacy of a computer-based hearing test and tailored hearing protection intervention. Int J Behav Med. 2006; 13(4):304-14.

15. Lusk SL, Ronis DL, Kazanis AS, Eakin BL, Hong O, Raymond DM. Effectiveness

of a tailored intervention to increase factory workers' use of hearing protection. Nurs Res. 2003 Sep-Oct; 52(5):289-95.

16. Brasil. Norma Regulamentadora no 7 do Capítulo V, Título II, da CLT. Programa de Controle Médico de Saúde Ocupacional. Última alteração realizada em 09 de maio de 1994 pela Portaria da SSMT $\mathrm{n}^{\circ} .8$.

17. Brasil. Portaria no. 3214 de 08 de junho de 1978. Aprova as Normas Regulamentadoras do Capítulo V, Título II, da CLT, relativas à segurança e medicina do trabalho. Diário Oficial [da] União. 06 de julho de 1978.

18. Svensson EB, Morata TC, Nylén P, Krieg EF, Johnson AC. Beliefs and attitudes among Swedish workers regarding the risk of hearing loss. Int $\mathrm{J}$ Audiol. 2004; 43(10):585-93.

19. Bramatti L. Ações educativas com enfoque positivo em programa de conservação auditiva e sua avaliação. [dissertação] Curitiba (PR): Universidade Tuiuti do Paraná; 2007.

20. Sartori E. Conhecimento e atitude de trabalhadores em relação à exposição a ruído no trabalho e à prevenção da perda auditiva. In: Morata TC. Caminhos para a saúde auditiva: ambiental - ocupacional. São Paulo: Plexus; 2005. p.109-23

21. Stephenson R, Merry CJ. A comparison and contrast of workers' vs. health and safety professionals' attitudes and beliefs about preventing occupational hearing loss. NIOSH poster presented at National Hearing Conservation Association Annual Conference Feb 25 - 27, 1999. Atlanta GA.

RECEBIDO EM: 19/06/2007

ACEITO EM: 28/05/2008

Endereço para correspondência:

Rua Porto Alegre, $581 \mathrm{E}$

Chapecó - SC

CEP: 89814-100

Tel: (49) 3322-3781

E-mail: lucianab @ clinicacomunicacao.brtdata.com.br 